\title{
FORGET: Pilot of an Innovative and Simple History Based Screening Tool for Dementia Community Clinics and Acute Medical Hospitals
}

\author{
Vellingiri Raja Badrakalimuthu \\ Parklands Hospital, Basingstoke, UK \\ Email: raja.badrakalimuthu@nhs.net
}

How to cite this paper: Badrakalimuthu, V.R. (2017) FORGET: Pilot of an Innovative and Simple History Based Screening Tool for Dementia Community Clinics and Acute Medical Hospitals. World Journal of Neuroscience, 7, 203-208.

https://doi.org/10.4236/wjns.2017.72015

Received: February 13, 2017

Accepted: March 18, 2017

Published: March 21, 2017

Copyright $\odot 2017$ by author and Scientific Research Publishing Inc. This work is licensed under the Creative Commons Attribution International License (CC BY 4.0). http://creativecommons.org/licenses/by/4.0/

\begin{abstract}
The aim of this study is to pilot FORGET as screening tool for dementia in community OP clinic and acute medical hospital assessments. Sample size included 30 each of memory clinic and acute medical hospital patients. Assessments included FORGET and MMSE. Psychometric test parameters were calculated for FORGET (Cut-off $>1$ in OP clinic and $>3$ in acute medical hospital). Of 30 referrals to memory clinic, 25 had dementia. A score $>1$ on FORGET had sensitivity $80 \%$, specificity $80 \%$, PPV $95.24 \%$, NPV $44.44 \%$, OR $16.00(\mathrm{p}=0.02)$ for diagnosis of dementia. Of 30 acute hospital referrals, 20 had dementia. A score $>3$ on FORGET had sensitivity $95 \%$, specificity $90 \%$, PPV $95 \%$ and NPV 90\%, OR $171(\mathrm{p}=0.0005)$. FORGET at a score of $>1$ in community and $>3$ in acute medical hospital is a useful screening tool for dementia.
\end{abstract}

\section{Keywords}

Dementia Screening, Primary Care, General Hospital

\section{Introduction}

Research conducted for Dementia UK: second edition shows that, in 2013, there were 815,827 people with dementia in the UK [1]. If current trends continue and no action is taken, the number of people with dementia in the UK is forecast to increase to $1,142,677$ by 2025 and 2,092,945 by 2051, an increase of $40 \%$ over the next 12 years and of $156 \%$ over the next 38 years. However, significant "diagnostic gap" for dementia, of more than a $50 \%$ exists between predicted prevalence and the actual GP registers across many regions in England, with only $46 \%$ of estimated dementia patients having a formal diagnosis locally [2]. This is due to a combination of factors like late patient recognition and presentation to the GPs, delayed referrals from the GPs to specialists and long waiting times to me- 
mory services. One measure to facilitate early diagnosis of dementia is to have robust and easy to administer screening tools which can be used with reliability at the primary point of contact which is GP surgery and acute medical hospital for elderly individuals.

Conventional screening tests such as Mini-Mental State Examination and 6CIT (Cognitive Impairment Test) are such tests used in primary and secondary care. They tend to lack focus on history and progression which are crucial evidences for progressive cognitive impairment in dementia. There is also training issue with some if these assessments and they add time towards clinical appointment slots offered in primary care. To overcome these drawbacks, it is important to develop a screening tool for dementia that can be used by health-care providers with ease and confidence.

\section{Method}

Analysis of cohorts referred to Basingstoke Older Peoples Mental Health Liaison Service over 4 months and 102 referrals (data available on request) has showed that duration of cognitive impairment (37.95 weeks vs6.6 weeks) and impaired activities of daily living (ADL; RR 1.73 (95\% CI 1.26 - 1.37). Hence a screening tool developed to facilitate use by health care professionals in hospital and across community will need to focus on duration of functional impairments and common symptoms of dementia. This has led to development of FORGET (Table 1). FORGET consists of 7-items, and takes about 5 - 7 minutes to administer. Each item carries a score of 1 leading to maximum score of 7 . Although the questions can be answered by carers and patients in early stages of dementia, the tool has been tested on carers. As the items in the screening tools are the most common issues that come up for discussion in clinical assessments, they are easy to capture within the clinic time and the items form the word FORGET, making it easy for clinician to remember.

Table 1. FORGET.

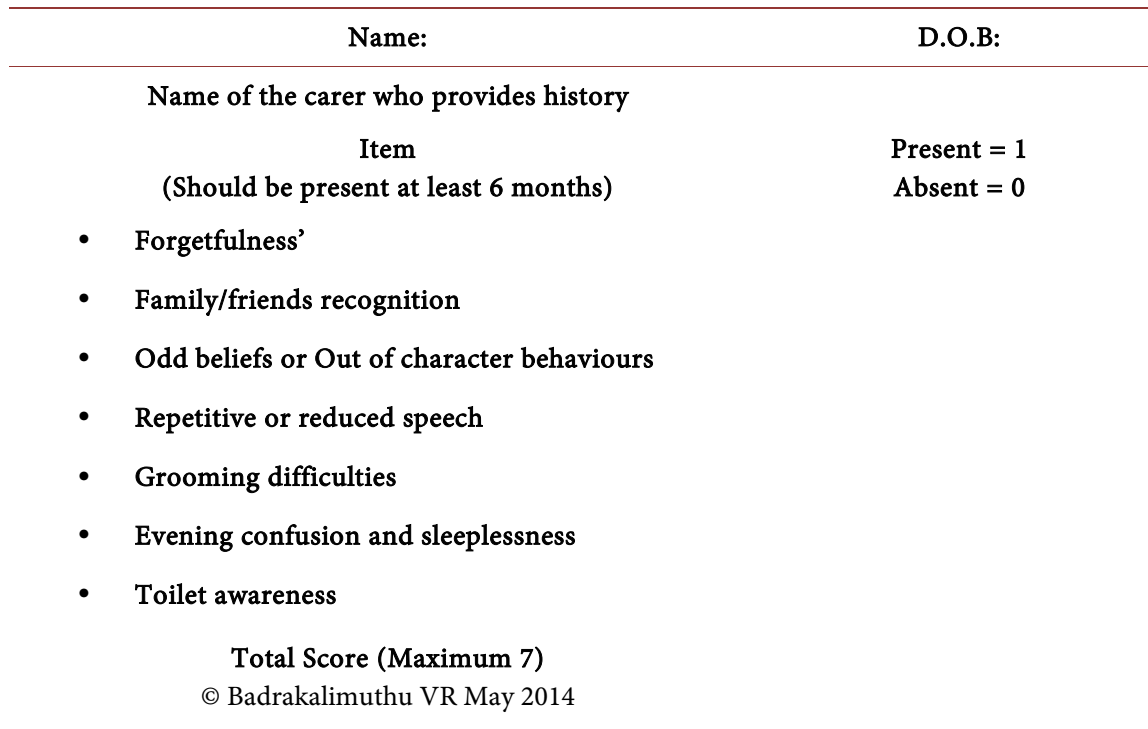


This study has been set up as a pilot study involving 30 consecutive referrals each to OP clinics in Parklands Hospital and OPMH Liaison Service from North Hants Hospital in Basingstoke. Junior doctors and nurses in this study have been trained in FORGET as well as conducting clinical and cognitive assessments in patients with cognitive impairment. Consultant psychiatrist who was blind to FORGET score offered diagnosis of dementia using ICD-10 criteria. Demographic data including age and gender as well as MMSE score has been collected for all individuals. Sensitivity, specificity, positive predictive value, negative predictive value and odds ratio has been calculated.

\section{Results}

Of the 30 patients each assessed in memory clinic and liaison, 25 in memory clinic and 20 in acute medical hospital have received diagnosis of dementia (Table 2). Average age of those diagnosed with dementia is memory clinic is $80.64(68$ - 92) and in liaison is 86.1 (77 - 103). Across both these settings, average age of those with dementia is found to be higher than those without dementia. Women present more with cognitive impairment and hence with dementia, which is common finding in similar studies in dementia. Sub-type of dementia has been made using combination of history, clinical assessment, cognitive assessment where possible using Addenbrooke's Cognitive Examination-Revised and neuroimaging. Alzheimer's disease dementia continues to remain most common type of dementia in elderly. Average FORGET score of those diagnosed with dementia is memory clinic is 2.72 and in liaison is 4.75.Average MMSE score of those diagnosed with dementia is memory clinic is 23.48 and in liaison is 11.1. FORGET scores and MMSE scores are much lower in those diagnosed with dementia compared to those without dementia across both community and acute hospital samples.

FORGET score of more than 1 has an odds ratio of $16(p=0.02)$ for diagnosis of dementia in community and has sensitivity of $80 \%$ and specificity of $80 \%$. FORGET score of more than 1 has an odds ratio of $19(p=0.06)$ for diagnosis of

Table 2. Differences between those diagnosed with dementia and those without dementia.

\begin{tabular}{ccccc}
\hline & \multicolumn{2}{c}{ Memory Clinic } & \multicolumn{2}{c}{ Acute Medical Hospital } \\
\cline { 2 - 5 } & Dementia & No dementia & Dementia & No dementia \\
\hline Number & 25 & 5 & 20 & 10 \\
& Alzheimer's $=17$ & & Alzheimer's $=14$ & Vascular 4 \\
Dementia sub-type & Vascular $=6$ & NA & DLB $=2$ & NA \\
Age & DLB $=1$ & & FTD $=0$ & \\
FTD $=1$ & & & $86.1(77-103)$ & $82.2(75-95)$ \\
Gender (Male) & $80.64(68-92)$ & $71.2(52-83)$ & $8(40 \%)$ & $5(50 \%)$ \\
FORGT score (Average) & $10(40 \%)$ & $4(80 \%)$ & 4.75 & 2.1 \\
MMSE (Average) & 2.72 & 1.2 & 11.1 & 22.2 \\
\hline
\end{tabular}


dementia in liaison and has sensitivity of $100 \%$ and specificity of $30 \%$. However if FORGET cut off is more than 3 , then odds ratio went up to $171(p=0.0005)$ and sensitivity becomes $95 \%$ as the specificity increases to $90 \%$. PPV, NPV and comparable odds ratios for MMSE are given in Table 3 and Table 4.

This study also looks at the value of adding MMSE to FORGET as screening. In community clinic sample MMSE score of less than 27 and FORGET score of more than 1 has a sensitivity of $72 \%$ and specificity if $80 \%$. In liaison sample MMSE score of less than 27 and FORGET score of more than 3 has a sensitivity of $95 \%$ and specificity if $100 \%$.

\section{Discussion}

This pilot study of FORGET as history-based screening tool for dementia demonstrates that in community sample, score of more than 1 provides sensitivity, specificity of $80 \%$, PPV of $95 \%$ and NPV of $44 \%$. In acute medical hospital sample, score of more than 3 provides sensitivity of $95 \%$, specificity of $100 \%$, PPV of $95 \%$ and NPV of $90 \%$.

Tangalos \& Smith et al. [3] report that MMSE cut-off score of 23 or less has a sensitivity of $69 \%$ and a specificity of $99 \%$. In the same study PPV is reported to be less than $35 \%$ and that participating physicians consider the MMSE of little value for routine screening in unselected populations. Hessler \& Bronner et al. [4] report from their study using 6-CIT that sensitivity and specificity for 6-CIT reaches values of 0.49 and 0.92 at the $7 / 8$ cut-off. They also suggest that the psychometric properties of 6-CIT does not suit itself to be a routine screening tool. In comparison to these two commonly used screening tests FORGET does have better sensitivity across community and acute hospital samples and better specificity in acute hospital sample. It also matches PPV with a value of $95 \%$.

Thus FORGET does prove to be a useful screening tool in screening for dementia in comparison with the familiar tools of cognitive screening such as MMSE or 6-CIT. Where the real advantage of FORGET is that it is based on history and hence would help the clinician ton have a focused and structured

Table 3. Comparing cut-offs and test parameters in memory clinic.

\begin{tabular}{|c|c|c|c|c|c|}
\hline Cut-offs & Odds Ratio & Sensitivity & Specificity & $\begin{array}{c}\text { Positive } \\
\text { Predictive Value }\end{array}$ & $\begin{array}{c}\text { Negative } \\
\text { Predictive Value }\end{array}$ \\
\hline Cut-off $>1$ & $\begin{array}{c}16.00^{*} \\
(95 \% \text { CI } 1.45-17.96) \\
p=0.02 \\
\mathrm{z}=2.264\end{array}$ & $\begin{array}{c}\mathbf{8 0 \%} \\
(95 \% \mathrm{CI} \\
59.29 \%-93.09 \%)\end{array}$ & $\begin{array}{c}\mathbf{8 0 \%} \\
(95 \% \mathrm{CI} \\
28.81 \%-96.70 \%)\end{array}$ & $\begin{array}{c}95.24 \% \\
(95 \% \mathrm{CI} \\
76.11 \%-99.21 \%)\end{array}$ & $\begin{array}{c}44.44 \% \\
(95 \% \text { CI } \\
13.97 \%-78.60 \%)\end{array}$ \\
\hline $\begin{array}{c}\text { Cut-off }>1 \& \\
\text { MMSE of } 27 \text { or less }\end{array}$ & $\begin{array}{c}10.2857 \\
(95 \% \text { CI } 0.9723-108.8114) \\
p=0.05 \\
\mathrm{z}=1.937\end{array}$ & $\begin{array}{c}72 \% \\
(95 \% \mathrm{CI} \\
50.61 \%-87.88 \%)\end{array}$ & $\begin{array}{c}\mathbf{8 0 \%} \\
(95 \% \mathrm{CI} \\
28.81 \%-96.70 \%)\end{array}$ & $\begin{array}{c}\mathbf{9 4 . 7 4 \%} \\
(95 \% \mathrm{CI} \\
73.90 \%-99.12 \%)\end{array}$ & $\begin{array}{c}36.36 \% \\
(95 \% \mathrm{CI} \\
11.15 \%-69.12 \%)\end{array}$ \\
\hline
\end{tabular}


Table 4. Comparing cut-offs and test parameters in Acute-Medical Hospital assessments.

\begin{tabular}{|c|c|c|c|c|c|}
\hline Cut-offs & Odds Ratio & Sensitivity & Specificity & $\begin{array}{c}\text { Positive } \\
\text { Predictive Value }\end{array}$ & $\begin{array}{c}\text { Negative } \\
\text { Predictive Value }\end{array}$ \\
\hline Cut-off $>1$ & $\begin{array}{c}19.133 \\
(95 \% \text { CI } 0.880-415.906) \\
p=0.06 \\
\mathrm{z}=1.879\end{array}$ & $\begin{array}{c}100 \% \\
(95 \% \mathrm{CI} \\
83.16 \%-100 \%)\end{array}$ & $\begin{array}{c}30 \% \\
(95 \% \mathrm{CI} \\
6.67 \%-65.25 \%)\end{array}$ & $\begin{array}{c}\mathbf{7 4 . 0 7 \%} \\
(95 \% \mathrm{CI} \\
53.72 \%-88.89 \%)\end{array}$ & $\begin{array}{c}100 \% \\
(95 \% \mathrm{CI} \\
29.24 \%-100.00 \%)\end{array}$ \\
\hline Cut-off $>3$ & $\begin{array}{c}171^{*} \\
(95 \% \text { CI } 9.569-3055.681) \\
p=0.0005 \\
\mathrm{z}=3.49\end{array}$ & $\begin{array}{c}\mathbf{9 5 \%} \\
(95 \% \mathrm{CI} \\
75.13 \%-99.87 \%)\end{array}$ & $\begin{array}{c}90 \% \\
(95 \% \mathrm{CI} \\
55.50 \%-99.75 \%)\end{array}$ & $\begin{array}{c}95 \% \\
(95 \% \mathrm{CI} \\
75.13 \%-99.87 \%)\end{array}$ & $\begin{array}{c}\mathbf{9 0 \%} \\
(95 \% \mathrm{CI} \\
55.50 \%-99.75 \%)\end{array}$ \\
\hline MMSE 27 or less & $\begin{aligned} 19.133 \\
(95 \% \text { CI } 0.88-415.90) \\
p=0.060 \\
\mathrm{z}=1.879\end{aligned}$ & & & & \\
\hline $\begin{array}{c}\text { Cut-off }>3 \& \\
\text { MMSE of } 27 \text { or less }\end{array}$ & $\begin{array}{c}273^{*} \\
(95 \% \text { CI } 10.197-7309.229) \\
p=0.0008 \\
\mathrm{z}=3.344\end{array}$ & $\begin{array}{c}95 \% \\
(95 \% \mathrm{CI} \\
75.13 \%-99.87 \%)\end{array}$ & $\begin{array}{c}100 \% \\
(95 \% \mathrm{CI} \\
69.15 \%-100.00 \%)\end{array}$ & $\begin{array}{c}100 \% \\
(95 \% \mathrm{CI} \\
82.35 \%-100.00 \%)\end{array}$ & $\begin{array}{c}\mathbf{9 0 . 9 1 \%} \\
(95 \% \mathrm{CI} \\
58.72 \%-99.77 \%)\end{array}$ \\
\hline
\end{tabular}

conversation with the patient and carer in understanding symptoms and impact of dementia. Another distinct advantage of FORGET is that it takes much shorter to complete FORGET compared to these tools. It will be time-saving tool for GPs in their surgeries and hospital doctors whilst completing their ward rounds. Another advantage is that unlike MMSE or 6-CIT the test asks for functional impairment and hence will help with formulating care needs for the individual with cognitive impairment.

The advantages of this study include paired FORGET and MMSE scores in community and acute hospital samples and independent assessment by a psychiatrist towards providing ICD-10 based clinical diagnosis blind to FORGET scores. Other advantage includes FORGET achieving sensitivity and specificity measures and better PPV compared to comparable screening tools used in clinical practice. This study also finds that combining FORGET with MMSE can be useful in screening and diagnosing dementia. This study is a pilot and hence incorporated sample size of 30 consecutive assessments in community and liaison. Hence it will need to be replicated using a bigger sample size in acute hospital and community setting. Such bigger studies will have to explore reliability of the tool; however since this is only a structured way of collecting history, and that training is not essential, reliability may not be a problem.

\section{Conclusions}

There is an urgent need to make screening processes for dementia easier, less time-consuming and sensitive so that it can be used by healthcare professionals in primary care and acute medical hospitals. This is crucial in early diagnosis of dementia; hence promoting opportunities for an individual with dementia to access appropriate pharmacological and non-pharmacological treatments as well as to make advance directives regarding health and well-being. 
This pilot study of FORGET an innovative history-based tool for screening dementia in community and acute medical hospital with a cut-off score of more than 1 in the former setting and more than 3 in the latter setting has good sensitivity, specificity as well as positive-predictive value. The values are comparable to cognitive assessment screening tools. In addition FORGET comes with distinct advantages of being easy to administer, less time-consuming and gives clinician perspective on functional impairment from cognitive problem. Hence FORGET can be recommended for routine use in screening for dementia in elderly patients presenting with symptoms of cognitive impairment in primary care and acute medical hospital settings.

\section{Acknowledgements}

Anthea Godleman, Memory Clinic Nurse; Michelle Porter \& Liz Nikiperowciz, Liaison Nurses; Dr. Ruth Nesbit FY2 trainee.

\section{References}

[1] Prince, M., Knapp, M., Guerchet, M., McCrone, P., Prina, M., Comas-Herrera, A. and Wittenberg, R. (2014) Dementia UK Update. Alzheimer's Society.

[2] Mapping the Dementia Gap. Alzheimer's Society, 2012.

[3] Tangalos, G.E., Smith, G.E., Ivnik, R.J., Petersen, R.C., Kokmen, E., Kurland, L.T., Offord, K.P. and Parisi, J.E. (1996) The Mini-Mental State Examination in General Practice: Clinical Utility and Acceptance. Mayo Clinical Proceedings, 71, 829-837. https://doi.org/10.4065/71.9.829

[4] Hessler, J., Bronner, M., Etgen, T., Ander, K., Forstl, H., Poppert, H., Sander, D. and Bickel, H. (2014) Suitability of 6-CIT as a Screening Test for Dementia in Primary Patients. Aging \& Mental Health, 18, 515-520. https://doi.org/10.1080/13607863.2013.856864

Submit or recommend next manuscript to SCIRP and we will provide best service for you:

Accepting pre-submission inquiries through Email, Facebook, LinkedIn, Twitter, etc. A wide selection of journals (inclusive of 9 subjects, more than 200 journals)

Providing 24-hour high-quality service

User-friendly online submission system

Fair and swift peer-review system

Efficient typesetting and proofreading procedure

Display of the result of downloads and visits, as well as the number of cited articles

Maximum dissemination of your research work

Submit your manuscript at: http://papersubmission.scirp.org/

Or contactwjns@scirp.org 